\title{
Simulations of Mode Division Multiplexed Free Space Optics with Photonics Traversal Filter using Multi-Mode Fiber
}

\author{
Prakash Poornachari, Kasthuri Palanichamy, Ganesh Madan M, Arul Prakash Samathuvamani
}

Department of Electronics Engineering, MIT Campus, Anna University, Chennai, India.

\begin{abstract}
The ever-increasing demands for ubiquitous connectivity for faster high-capacity communication systems has driven the quest for sixth-generation(6G) communication systems. It is expected to address the need for higher capacity, lower latency systems with higher Quality of Service (QoS) than fifth-generation 5 G communication systems. Aerial Access Networks (AANs) have attracted attention and are considered as a potential solution for $6 \mathrm{G}$ systems. Heterogeneous networks with fiber and Free Space Optics (FSO). FSO front haul architecture is expected to meet the demands for the low-cost deployment of 6G networks. However, an increase in transmission capacity of FSO by mode division multiplexing to meet the needs for 6G communication has been least explored. Improvements in fiber multiplexing and demultiplexing techniques have enabled the possibilities for novel Mode Division Multiplexing (MDM) techniques to improve the capacity of fiber networks at a low cost. In this work, we have discussed the design of a novel photonics traversal filter to perform Mode Division Multiplexing in Multimode Fiber (MMF), thereby increasing the fiber's capacity. The performance of Mode Division Multiplexed FSO links is further examined through simulations to identify its capabilities to meet the demands of $6 \mathrm{G}$ communication systems.
\end{abstract}

Keywords: $6^{\text {th }}$ generation communication systems; Multimode Fiber; Mode Division Multiplexing; Photonics Filter; Multiplexing; Demultiplexing

\section{Simulacije delitve rodov multipleksirane optike prostega prostora z uporabo večrodovnega vlakna}

\begin{abstract}
Izvleček: Vedno večje zahteve po vseprisotni povezljivosti za hitrejše komunikacijske sisteme z visoko zmogljivostjo so spodbudile iskanje komunikacijskih sistemov šeste generacije (6G). Pričakuje se, da bo zagotavljal večjo zmogljivostjo, manjšo zakasnitev in višjo kakovostjo storitev (QoS) kot komunikacijski sistemi pete generacije 5G. Kot potencialna rešitev za sisteme 6G se omenja prostorsko dostopna omrežja (Aerial Access Networks - AANs). Heterogena omrežja z optičnimi vlakni in optiko v prostem prostoru (FSO). Pričakuje se, da bo arhitektura FSO izpolnjevala zahteve po nizkocenovnem uvajanju omrežij 6G. Kljub temu je bilo povečanje prenosne zmogljivosti FSO z multipleksiranjem delitve rodov za potrebe komunikacij 6G najmanj raziskano. Izboljšave tehnik multipleksiranja in demultipleksiranja optičnih vlaken so omogočile možnosti za nove tehnike multipleksiranja delitve rodov (MDM) za izboljšanje zmogljivosti optičnih omrežij z nizkimi stroški. V tem članku smo obravnavali zasnovo novega fotonskega potovalnega filtra za izvajanje multipleksiranja delitve rodov v večrodnih vlaknih (MMF) in s tem povečanje zmogljivosti vlaken. Zmogljivosti za izpolnjevanje zahtev komunikacijskih sistemov $6 \mathrm{G}$ so bile raziskane s simulacijami.
\end{abstract}

Ključne besede: 6 . generacija komunikacijskih sistemov; večrodna vlakna; milipleksiranje delitve rodov; fotonski filter; multipleksiranje; demultipleksiranje

*Corresponding Author's e-mail:prakashp79@gmail.com

\section{Introduction}

There has been an exponential increase in the amount of data being transferred due to the ease of use of intel- ligent devices. The number of smartphones is expected to surpass 8 billion by 2022 [1]. The mobile data traffic is expected to increase seven-fold and reach 77.5 Exa- 
bytes per month $[2,3]$. The very rapid development of technologies like Artificial Intelligence (AI), Internet of Things (IoT), Virtual Reality (VR) has led to a massive increase in data traffic. It is predicted that the existing communications and network infrastructure would not be sufficient to handle the amount of data expected to be transferred. The fifth-generation communication is currently being deployed and is aimed at providing faster, high-capacity transmission. By 2030, 5G communication would reach its limits, requiring higher capacity systems with lower latency. Artificial Intelligence would play a significant role in $6 \mathrm{G}$ networks providing network adaptation and management. [4]. 6G should meet the demands for a fully digital and connected world. $6 \mathrm{G}$ networks would have high bitrate, low latency, high energy, spectral efficiency, high Quality of Service (QoS), and high reliability.

FSO is one of the key technologies expected to enable a $6 \mathrm{G}$ wireless communication system [5]. Backhaul connectivity should have a high capacity supporting large volumes of traffic. Remote geographic locations, deployment complexities in congested cities have increased the deployment cost of fifth-generation communication systems. Optical Fibers and Free Space Optical Communication Systems (FSO) would meet the demands for $6 \mathrm{G}$ communication systems $[6,7]$. FSO would support high-capacity connectivity in hard-todeploy places proving to be an efficient communication technique for front and backhaul. Mode Division Multiplexing has been least explored to increase the capacity of fibers. Mode Division Multiplexing can result in modern, adaptive systems directly combining components like an amplifier for all channels [8]. This paper would discuss the role of FSO in $6 \mathrm{G}$ communication and provide multiplexing techniques for reliable high capacity FSO communication debating the challenges and future research to be performed.

Sending signals in strands of glass called fibers is Optical Fiber Communication. The fiber consists of center glass through which photons are guided by a cladding that traps the photons inside the core. SingleMode Fiber (SMF) has a small core diameter, allowing only one mode of light to propagate. Multimode fibers have a large core diameter which allows multiple ways of light to propagate. Modes of fiber are defined by the Helmholtz equation, an extension of Maxwell's equations which gives Laplacian relation between amplitude and wavenumber. Among various modes in optical fibers, Linearly Polarized modes (LP Modes) are used in Mode Division Multiplexing. LP modes are typically used in graded fibers, LP mode field components in the direction of propagation are small compared to the components perpendicular to the direction of propagation. The transmitter and receiver characteris- tics of Free Space Optics (FSO) systems are comparable to optical fibers.

We have designed and simulated a novel photonics traversal filter using Multi-Mode Fiber, and the capacity of the channel is increased by using Mode Division Multiplexing (MDM). The use of a single multimode fiber provides space demultiplexing to eliminate optical interference and time delays between filter taps.

\section{Mode division multiplexing}

Mode Division Multiplexing utilizes multiple modes as different transmission channels within fibers. As a result, mode Division Multiplexing can increase the bandwidth of transmission, and it'san alternate solution to Multi-Core Fiber [9].

\subsection{Tunable mode division multiplexing}

The block diagram for the tunable multimode fiber for mode division multiplexing is shown in Figure 1.

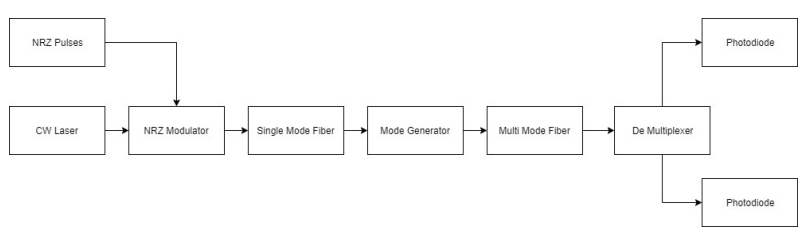

Figure 1: Tunable Multimode Fiber with Mode Division Multiplexing. Tunability of the filter is obtained by changing the incident angle of different beams at MMF.

The input signal is generated using Pseudo-Random Binary Source and encoded with the Non-Return to Zero (NRZ) pulse. The optical carrier signal used here is Continuous Wave Laser(CW laser) which gets modulated with the binary signal using Mach Zehnder modulator (MZM). [10-12]

Photonics filter has been used for various RF signal processing tasks [13]. Microwave photonics filter have provided significant improvement in performance when compared to conventional electrical RF filters. Microwave photonics filter provides high bandwidth with low loss and provides increased tunability and flexibility. Our photonics filter is based on a single wavelength multimode optical delay module [14]. The Photonics traversal filter acts as an optical delay line module. An optical carrier of a single wavelength is split into several beams and is incident at the Multi-Mode Fiber (MMF) at different incident angles. As a result, different spatial modes can be excited within the core MMF region, which acts as filter taps. Modal dispersion acts as a time delay between adjacent taps. By changing the incident angle of the light from SMF, the modes can be tuned. 
Table 1. Simulation Parameters.

\begin{tabular}{|l|l|}
\hline Parameters & Values \\
\hline Data Rate & $10 \mathrm{Gbps}$ \\
\hline Wavelength used & $1550 \mathrm{~nm}$ \\
\hline Laser Power & Ten $\mathrm{dBm}$ \\
\hline Line width & $10 \mathrm{MHz}$ \\
\hline Attenuation (MMF) & $1.8 \mathrm{~dB} / \mathrm{km}$ \\
\hline PIN Responsivity & $1 \mathrm{~A} / \mathrm{W}$ \\
\hline
\end{tabular}

The input from the CW laser is fed into the mode generator. For simulation, the mode generator is used as a transversal filter that converts single-mode into multimode. The generated multimode that are orthogonal to each other are multiplexed using MDM. The multiplexed signal is then fed into Multimode fiber. The simulation layout of the tunable multimode optical delay line with MDM is shown in Figure 2. For simulation, spatial Multiplexer is used as Traversal Photonics Filter, which is then fed into MMF. The use of a single multimode fiber provides space demultiplexing to eliminate optical interference and time delays between filter taps using modal dispersion. The delayed signals from the MMF are demultiplexed using a spatial demultiplexer. Finally, the optical signal from the demultiplexer is received by the photodiodes. The simulation parameters are shown in Table 1.

Figure 2: Layout of Tunable Multimode Fiber with

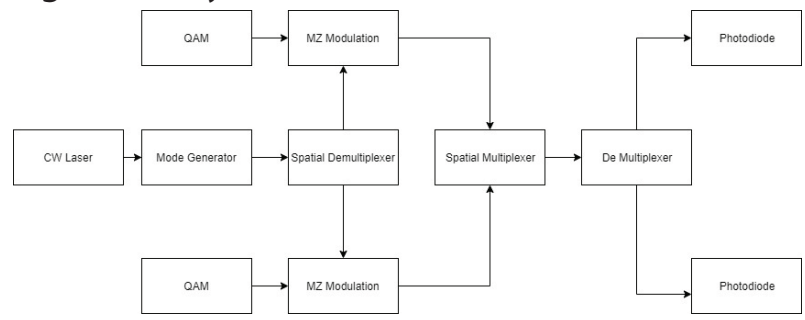

Mode Division Multiplexing

\section{Simulation results}

\subsection{Transmitted modes}

The Linearly Polarized (LP) modes, designated as LPIm, are good approximations formed by exact modes TM, $T E, E H$, and HE. The mode subscripts' $\mathrm{I}^{\prime}$ and ' $\mathrm{m}$ ' describe the electrical field intensity profile. There are ' $2 \mathrm{l}$ ' field maxima along the fiber core circumference and ' $m$ ' field maxima along the fiber core radial direction. The LP modes are generated by setting the power ratio parameter in the multimode generator as $(1,2)$. Similarly, we can generate Laguerre Gaussian (LG) modes and Hermite Gaussian (HG) modes. In this work, two$\operatorname{LP}$ modes, $\operatorname{LP}(0,1)$ and $\operatorname{LP}(1,1)$, have been taken, and their performance in terms of BER and Quality factor is analyzed based on different length parameters.

\subsection{Transmitted LP Mode $(0,1)$ :}

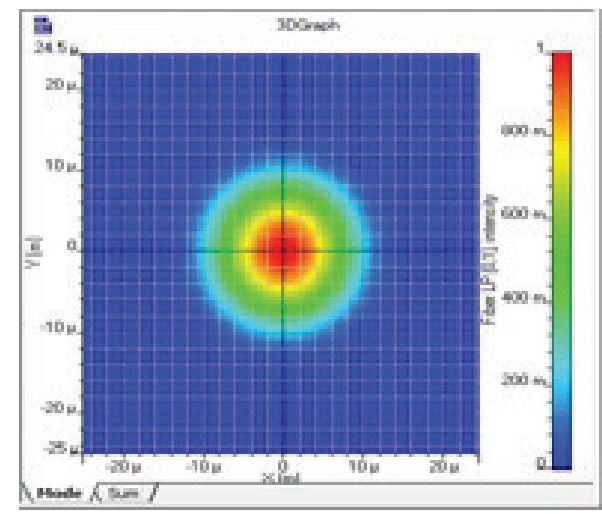

Figure 3: $\operatorname{LP}(0,1)$

From Figure 3, $\operatorname{LP}(0,1)$ indicates no maxima around the fiber core circumference and single field maxima along the fiber core radial direction.

\subsection{Transmitted LP Mode (1, 1):}

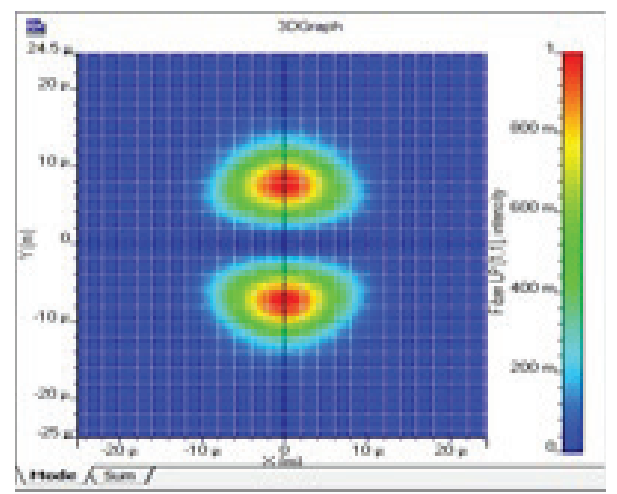

Figure 4: $\operatorname{LP}(1,1)$

From Figure4, LP $(1,1)$ indicates two field maxima around the fiber core circumference and single field maxima along the fiber core radial direction. Figure 5 and Figure 6 tells about $\operatorname{LP}(1,2)$ and $\operatorname{LP}(1,3)$.

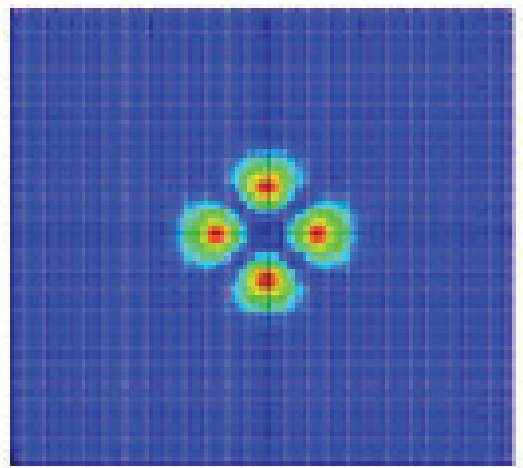

Figure 5: $\operatorname{LP}(1,2)$ 


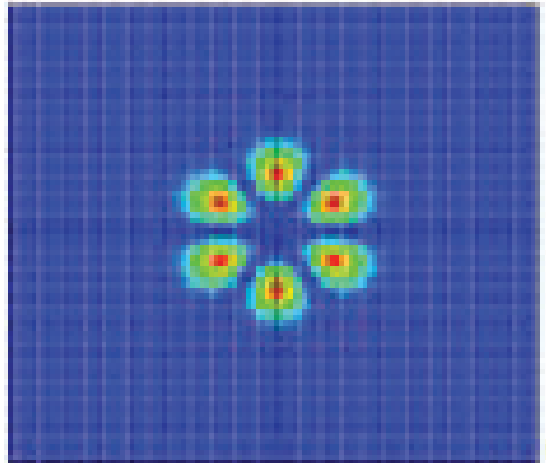

Figure 6: $\operatorname{LP}(1,3)$

\subsection{Modes after multiplexing:}

The modes $\operatorname{LP}(0,1)$ and $\operatorname{LP}(1,1)$ are multiplexed using Ideal mux. An ideal Multiplexer is equivalent to a perfect adder. There is no power splitting or filtering when in an Ideal Mux. The modes after multiplexing are visualized by using a spatial visualizer. The modes after multiplexing are shown in Figure 7.

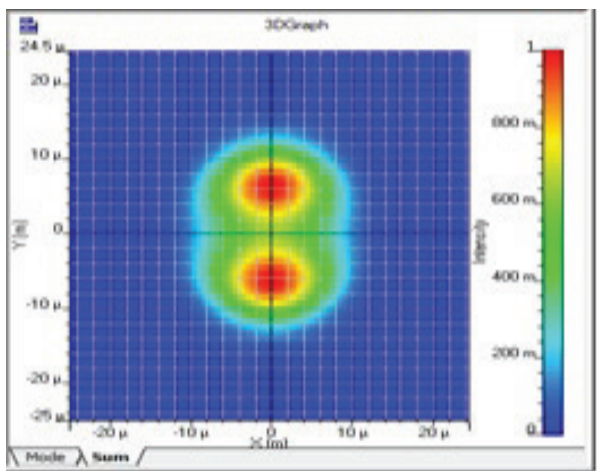

Figure 7: Multiplexed $\operatorname{LP}(0,1)$ and $\operatorname{LP}(1,1)$

\section{Free Space Optics}

Free Space Optics uses photonics that propagates through the air like a wireless transmission. Free Space Optics has all the advantages of wireless radio transmission with a high transfer rate and bandwidth. Still, Free Space Optics is limited to short-range communications at a direct line of sight. The basic architecture of Free Space Optical Communication Systems is given in Figure 8.

The modulated Input Pulse is fed into the MZM, which converts the electrical pulses into an equivalent optical signal. The photonic signal generated from the MZM is then transmitted into free space with the help ofan optical lens so that the dispersion of light is minimal. Free Space Optics is affected by weather conditions and

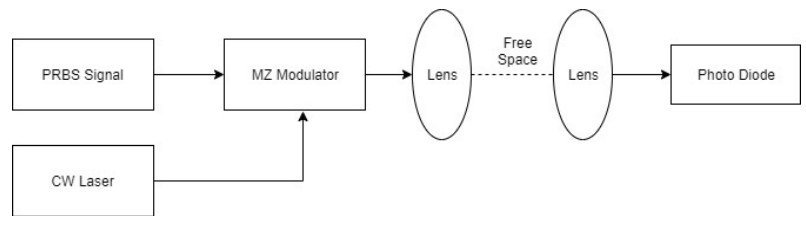

Figure 8. Basic Architecture of Free Space Optics

other atmospheric factors, which reduces the transmitting distance of the signals.

\subsection{Radio over free space optics}

Radio over FSO (RoFSO) is an extension of Radio over Fiber techniques in which RF baseband signals make use of optical light as carriers for distribution over networks [15]. For transmission over the atmosphere, Radio over Fiber signals is amplified and emitted into free space. The demerits of RoFSO technology are its dependence on atmospheric conditions, which can be solved using various dispersion compensation techniques presented in this paper.

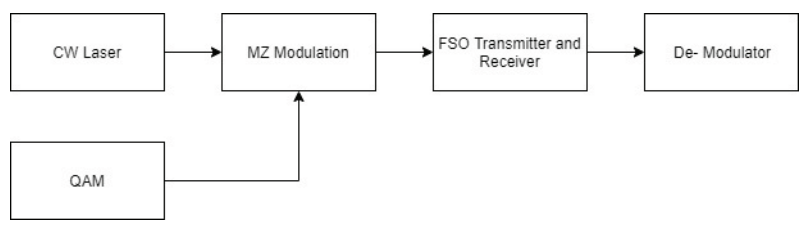

Figure 9. Radio over Free Space Optics where modulated signals are transmitted over free air.

Mm-Wave frequencies are limited by range. With its limited range of capabilities, and adaptive fronthaul architecture is required. Fibers combined with RoFSO provide the flexibility to network designers to design a system that can be adapted to the design environment.

\subsection{FSO based backhaul and front haul architecture}

In fifth-generation wireless architecture, fibers are being deployed for front haul because of their higher capacity. Previously, it is discussed that using Multi-Mode Fibers, the bandwidth of the fibers can be increased. Similarly, we have proposed a design methodology where RoFSO can be deployed in fronthaul and Backhaul as per design needs. 6Gcommunication systems are expected to meet the demands of a fully digital and connected world. High-speed, high-capacity communication with low latency is expected to be the basic norm to meet the needs of technologies such as VR and loT. Remote geographic locations have made the deployment of $5 \mathrm{G}$ internet communication more costly and complex. $6 \mathrm{G}$ communication systems should have flexibility and adaptability in deployment [16]. Aerial Access Networks (AANs) are a potential solution for 
6G communication. Unlike terrestrial wireless communication networks, AANs use satellites and airships to deploy networks in hard-to-reach places. AANs are expected to work synchronously with existing terrestrial wireless communication methodologies. FSO can connect Core Office with satellites which in turn beam signal to remote $6 \mathrm{G}$ antenna nodes. FSO plays a significant role in inter-satellite communication and groundsatellite communication.

Also, FSO could significantly replace fibers in metro cities where the deployment of fibers is challenging due to congestion. FSO can be used as a medium of transmission instead of fibers providing flexibility to network designers.

\section{High-capacity Ro-FSO transmission with mode division multiplexing}

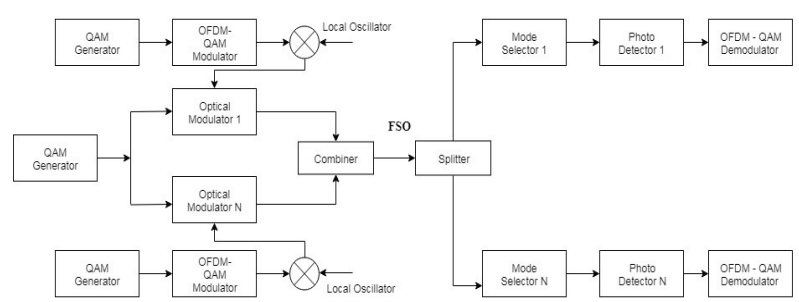

Figure 10: High-Capacity Ro-FSO Transmission with Mode Division Multiplexing.

A schematic diagram of the proposed hybrid highspeed Ro-FSO transmission system is shown in Figure 10. In the proposed system, Laguerre Gaussian/Hermite Gaussian was multiplexed through free space. Two independent $40 \mathrm{GHz}$ radio signals were modulated using a 4-level Quadrature Amplitude Modulation (QAM) followed by modulation by 512 OFDM subcarriers. The purpose of the Orthogonal Frequency Division Multiplexing(OFDM) modulation is to reduce the multipath fading effect incurred during the transmission through the FSO link [17]. The OFDM approach divides the data over a vast number of sub-carriers, which are separated from each other at narrow frequencies.

The OFDM signal was then modulated at $7.5 \mathrm{GHz}$ by using Quadrature Modulator (QM). This OFDM-QM modulated signal was then fed to a lithium niobate modulator which modulated the experimental LG/HG modes at $40 \mathrm{GHz}$. The modulator is assumed to preserve the modal stability of the channels. The output from the channels was transmitted over the FSO link.

The modes were demultiplexed using a spatial photodetector wherein an inner circular aperture of $5 \mathrm{~cm}$ was used to extract the modes. The received power between the apertures was adjusted such that the intensities on both the circular and outer apertures were equal. A 40 $\mathrm{GHz}$ was applied after the photodetector using a mixer to recover the Sub Carrier Multiplexing (SCM) signal. Finally, the output signal after the mixer was fed to the OFDM demodulator followed by the Quadrature Multiplexing (QM) demodulator to recover the original data. Given table shows the constellation plot of various modes after $1 \mathrm{~km}$ of FSO transmission. Table 2 shows the constellation diagram of Ro Direct Detection OFDM (DD-OFDM) 4-LG modes. Table 3 shows the constellation diagram of RoFSO DD-OFDM 4-HG modes. Future work is to deploy IIR based post dispersion compensation methodology to increase performance [18]. The proposed photonics filter can be deployed along with opto-electronics oscillator in order to get a low phase noise, however further work needs to be done to evaluate the performance of the filter in above configuration [19].

Table 2. Constellation Diagram of RoFSO DD-OFDM (4LG Modes).

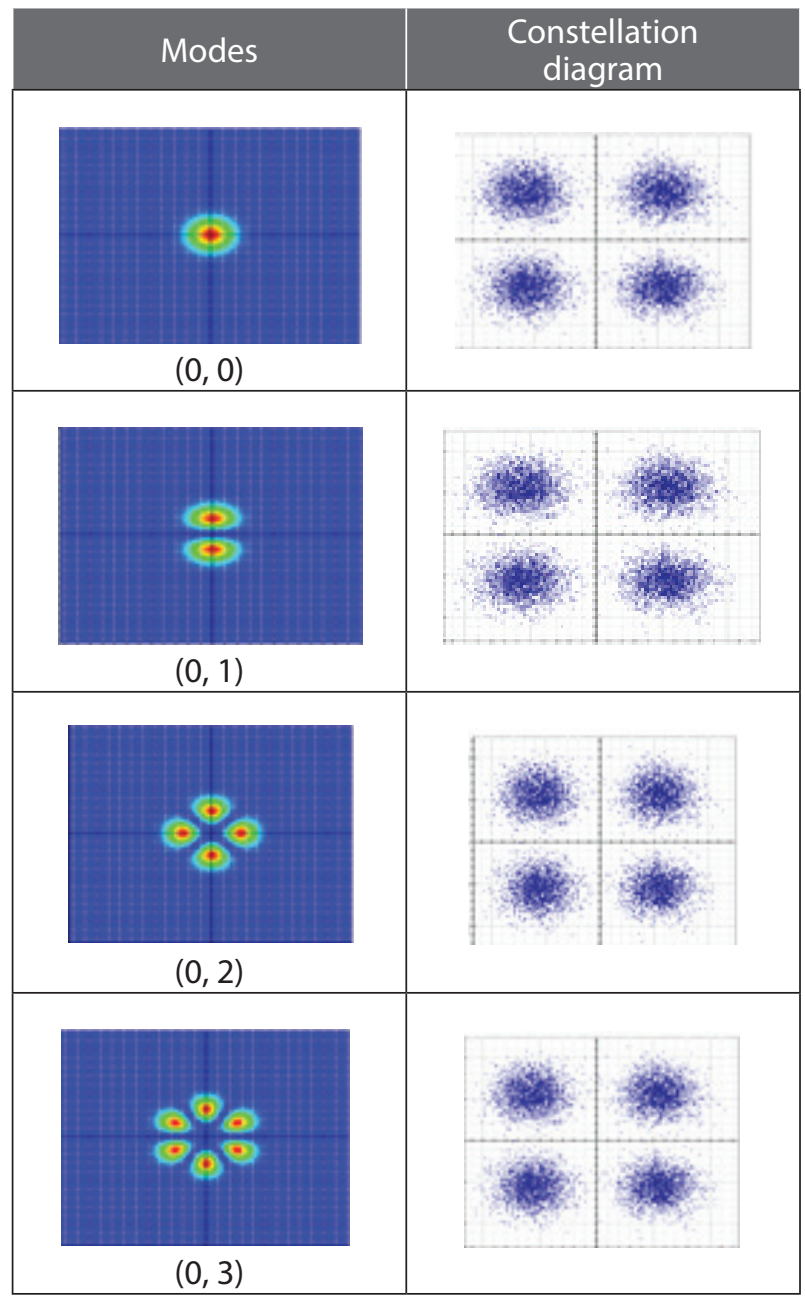

Table 3. Constellation Diagram of RoFSO DD-OFDM (4 HG Modes) 


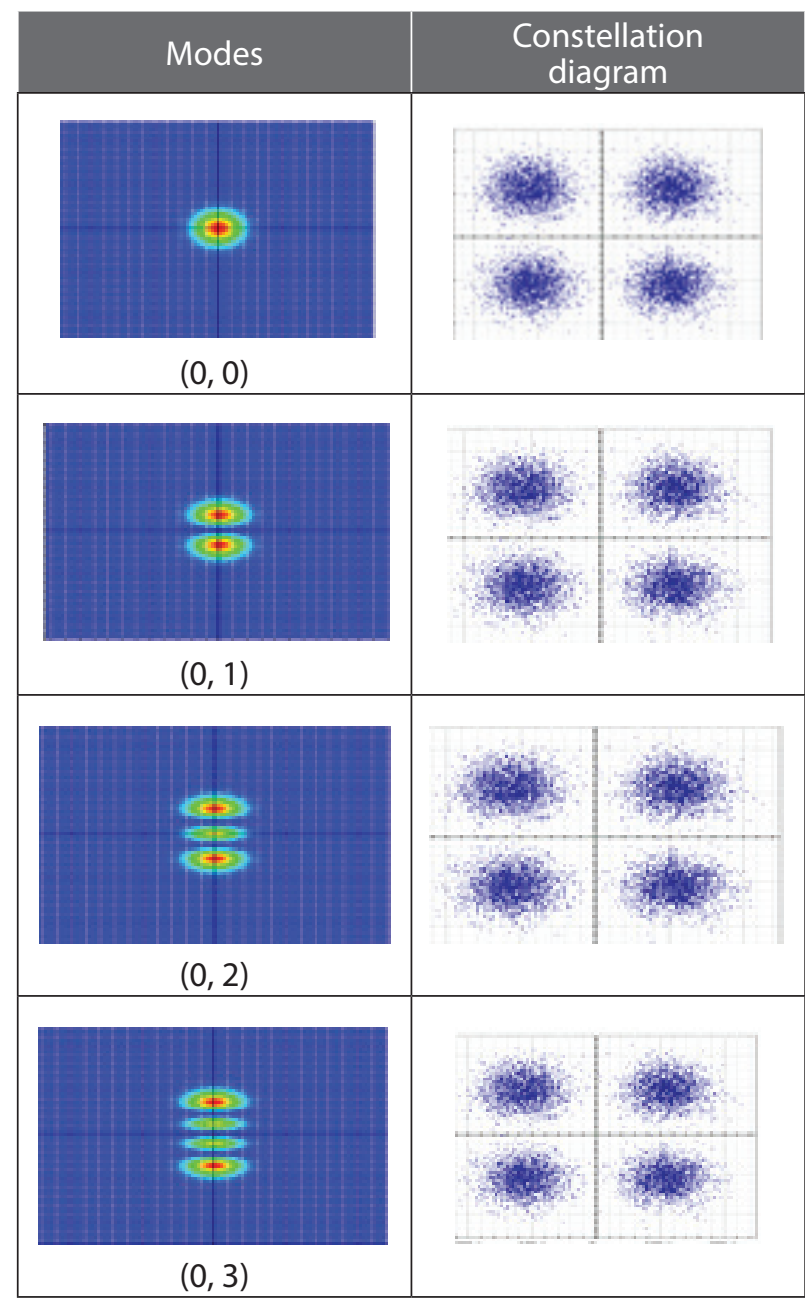

\section{Conclusion}

A design of novel photonics traversal filter to perform simulations of Mode Division Multiplexing in Multimode Fiber to increase the capacity of fiber is proposed. Model dispersion in the MMF is used as the time delay between filter taps. By using a single wavelength of $1550 \mathrm{~nm}$, the capacity of the channel is increased by mode division multiplexing. We have proposed a design for FSO based fronthaul and backhaul architecture in next-generation 6G communication. We simulated various modes in multimode fiber in both FSO based and fiber-based network designs. Dispersion characteristics of FSO in longdistance transmission and higher capacity transmission need to be examined. Future works need to be done to verify the dispersion compensation performance of IIR based filters in FSO based transmission medium.

\section{References}

1. "Mobile statistics report 2021 - 2025", Radicati, Jan. 2021, [online] Available:Microsoft Word - Mo- bile Statistics Report, 2021-2025 Executive Summary.docx (radicati.com)

2. "Cellular networks for massive loT Enabling low power wide area applications," Stockholm, Sweden:Ericsson, Jan. 2016, [online] Available: https://www.ericsson.com/en/reports-and-papers/white-papers/cellular-networks-for-massive-iot-enabling-low-power-wide-area-app

3. Batagelj, Boštjan, Vijay Janyani, and Sašo Tomažič. "Research challenges in optical communications towards 2020 and beyond." Informacije Midem 44.3 (2015): 177-184. MIDEM_44(2014)3p177.pdf (midem-drustvo.si)

4. Yang, Helin, et al. "Artificial-Intelligence-Enabled Intelligent 6G Networks." IEEE Network 34.6 (2020): 272-280.

https://doi.org/10.1109/MNET.011.2000195

5. Chowdhury, Mostafa Zaman, et al. "The role of optical wireless communication technologies in 5G/6G and loT solutions: Prospects, directions, and challenges." Applied Sciences 9.20 (2019): 4367.

https://doi.org/10.3390/app9204367

6. M. A. Ilgaz, A. Lavric, T. Odedeyi, I. Darwazeh, and B. Batagelj, "Adjustable testing setup for a single loop opto-electronic oscillator with an electrical bandpass filter," in Turkish Journal of Electrical Engineering and Computer Sciences, vol. 28, no. 3, pp. 1293-1302.

https://doi.org/10.3906/elk-1907-186

7. C. Liu, Z. Deng, X. Liu and X. Luo, "A Wideband Bandpass Filter with Broad Stopband and UltraWide Reflectionless Range for 5G Applications," 2019 IEEE MTT-S International Microwave Symposium (IMS), Boston, MA, USA, 2019, pp.834-837, https://doi.org/10.1109/MWSYM.2019.8700856.

8. Arık, Sercan Ö., Keang-Po Ho, and Joseph M. Kahn. "Group delay management and multiinput multioutput signal processing in mode-division multiplexing systems." Journal of Lightwave Technology 34.11 (2016): 2867-2880.

https://doi.org/10.1109/JLT.2016.2530978

9. Samir, A., and B. Batagelj. "A seven-core-fiber spectral filter based on LP01-LP01 mode coupling." Optoelectron. Adv. Mater.-Rapid Commun. 11.11/12 (2017): 628-32.

10. Kuleshov, N. V., et al. "CW laser performance of $\mathrm{Yb}$ and Er, Yb doped tungstates." Applied Physics B 64.4 (1997): 409-413.

11. Koplow, Jeffrey P., Dahv AV Kliner, and Lew Goldberg. "Single-mode operation of a coiled multimode fiber amplifier." Optics letters 25.7 (2000): 442-444.

https://doi.org/10.1364/ol.25.000442

12. Wang, Pengfei, et al. "Investigation of singlemode-multimode-single-mode and single- 
mode-tapered-multimode-single-mode fiber structures and their application for refractive index sensing." JOSA B 28.5 (2011): 1180-1186.

13. Liu, Xiaojuan, et al. "Tunable Multimode Optical Delay Line for Single-Wavelength Microwave Photonic Transversal Filter." 2018 International Topical Meeting on Microwave Photonics (MWP). IEEE, 2018. https://doi.org/10.1109/MWP.2018.8552882

14. Fok, Mable P., and Jia Ge. "Tunable multiband microwave photonic filters." Photonics. Vol. 4. No. 4. Multidisciplinary Digital Publishing Institute, 2017.

https://doi.org/10.3390/photonics4040045

15. Batagelj, Boštjan, et al. "Convergence of fixed and mobile networks by radio over fibre technology." Informacije MIDEM 41.2 (2011): 144149. www.midem-drustvo.si/Journal papers/ MIDEM_41(2011)2p144.pdf (midem-drustvo.si)

16. Chowdhury, Mostafa Zaman, et al. "6G wireless communication systems: Applications, requirements, technologies, challenges, and research directions." IEEE Open Journal of the Communications Society 1 (2020): 957-975.

https://doi.org/10.1109/OJCOMS.2020.3010270

17. Bekkali, Abdelmoula, et al. "Transmission analysis of OFDM-based wireless services over turbulent radio-on-FSO links modeled by gamma-gamma distribution." IEEE photonics journal 2.3 (2010): 510-520.

https://doi.org/10.1109/JPHOT.2010.2050306

18. Kasthuri Palanichamy, Prakash Poornachari, and M. Ganeshmadhan. "Performance Analysis of Dispersion Compensation Schemes with Delay Line Filter."Informacije MIDEM 50.4 (2021): 285-292. Performance Analysis of Dispersion Compensation Schemes with Delay Line Filter | Palanichamy | Informacije MIDEM (midem-drustvo.si)

19. A. Liu et al., "Spurious Suppression in MillimeterWave OEO With a High- Q Optoelectronic Filter," in IEEE Photonics Technology Letters, vol. 29, no. 19, pp. 1671-1674, 1 Oct.1, 2017, https://doi.org/10.1109/LPT.2017.2742662.

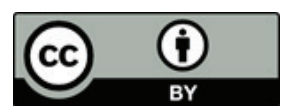

Copyright $\odot 2021$ by the Authors. This is an open access article distributed under the Creative Commons Attribution (CC BY) License (https://creativecommons.org/licenses/by/4.0/), which permits unrestricted use, distribution, and reproduction in any medium, provided the original work is properly cited.

Arrived: 16. 06. 2021

Accepted: 12. 10. 2021 